\title{
Intraoperative airway obstruction caused by dissection of the internal wall of a reinforced endotracheal tube \\ - A case report -
}

\section{Yuseon Cheong, Beomsang Hwang*, Innam Kim, Tsongbih Chang, Seongsik Kang, and Minsoo Kim}

Received February 14, 2017

Revised June 12, 2017

Accepted June 19, 2017
Department of Anesthesiology and Pain Medicine, Kangwon National University Hospital, Chuncheon, *Department of Anesthesiology and Pain Medicine, Yes Hospital, Seoul, Korea

\author{
Corresponding author \\ Minsoo Kim, M.D. \\ Department of Anesthesiology \\ and Pain Medicine, Kangwon \\ National University Hospital, 156, \\ Baengnyeong-ro, Chuncheon 24289, \\ Korea \\ Tel: 82-33-258-9130 \\ Fax: 82-33-258-9099 \\ E-mail: kmspain@kangwon.ac.kr
}

\begin{abstract}
Endotracheal intubation is the gold standard for airway management in general anesthesia. However, airway patency is not guaranteed by keeping the endotracheal tube (ETT) in place. Sometimes, the ETT itself may become a cause of airway obstruction; there are some reports on airway obstruction related to reinforced tube malfunction. We report a rare case with an obstruction of reinforced endotracheal tubes caused by dissection of the internal wall. Recognition of the possibility of airway obstruction due to a rare cause and monitoring patients vigilantly during anesthesia is very important for patient safety.
\end{abstract}

Key Words: Airway obstruction, Dissection, Endotracheal tube.
Endotracheal intubation is generally performed to access and protect the airway, and it has become a routine procedure in general anesthesia. However, intubation is not a risk-free procedure. Furthermore, obstruction of an endotracheal tube (ETT) is a potentially life-threatening event [1]. Intraoperative ventilation failure may occur because of various causes such as patients' respiratory diseases, types of operation and patient's position during the operation, and malfunctioning of the anesthesia machine or equipment. ETT obstruction can result from kinking or biting of the tube, foreign body aspiration, or thick or inspissated secretions in the lumen. Rarely, ETT problems, such as herniation of the cuff, dissection, or detachment of the internal wall, can cause obstruction [1]. We report an unusual case of ETT obstruction caused by dissection of the internal wall of a reinforced tube.

\section{CASE REPORT}

A 67-year-old woman $(164 \mathrm{~cm}, 68 \mathrm{~kg})$ who was previously healthy, except for being a hepatitis C virus carrier, was scheduled for a posterior lumbar interbody fusion because of lumbar spondylolisthesis and spinal stenosis. After using standard monitoring methods, including electrocardiography, a non-invasive blood pressure measuring device, and pulse oximetry; $0.2 \mathrm{mg}$ glycopyrrolate, $20 \mathrm{mg}$ lidocaine, and $120 \mathrm{mg}$ propofol were injected intravenously. After confirmation of unconsciousness, rocuronium $40 \mathrm{mg}$ was injected for paralysis and 2 minimum alveolar concentration (MAC) of sevoflurane with $100 \% \mathrm{O}_{2}(>5 \mathrm{~L} / \mathrm{min})$ were administered via face mask with manual ventilation. Under direct laryngoscopy, reinforced ETT (Mallinckrodt ${ }^{\circledR}$, Covidien Inc., USA) with 7.0-mm internal diameter was intubated without difficulty. Normal breath sounds were heard equally in both lungs. The ETT was fixed at $21 \mathrm{~cm}$ on the mouth angle. The lungs were mechanically ventilated (volume-controlled mode with tidal volume $500 \mathrm{ml}$ and respiratory rate 12 breaths/min) using Dräger Primus Workstation (Dräger Medical, Germany). The anesthesia was maintained with 1 MAC sevoflurane and a

This is an Open Access article distributed under the terms of the Creative Commons Attribution Non-Commercial License (http://creativecommons.org/licenses/by-nc/4.0) which permits unrestricted non-commercial use, distribution, and reproduction in any medium, provided the original work is properly cited. 
mixture of $1.5 \mathrm{~L}$ to $1.5 \mathrm{~L}$ of $\mathrm{O}_{2}$ and $\mathrm{N}_{2} \mathrm{O}$. Five minutes after intubation, the patient was stable with $\mathrm{ETCO}_{2} 35 \mathrm{mmHg}$, peak inspiratory pressure (PIP) $17-18 \mathrm{cmH}_{2} \mathrm{O}$, and $\mathrm{SpO}_{2} 99 \%$. After the patient was placed in a prone position, there was a mild increase in PIP to $20 \mathrm{cmH}_{2} \mathrm{O}$. However, lung sounds were normal. Thirty minutes after the patient's position changed, the PIP was gradually increased to $24 \mathrm{cmH}_{2} \mathrm{O}$ and the tidal volume was decreased to $350 \mathrm{ml}$. The lung sounds were heard equally in both lungs without wheezing. Ventolin was administered for bronchodilation, and rocuronium (10 mg) was injected intravenously for muscle relaxation; however, they produced almost no effect. There was no kinking or biting of the tube in the mouth, but the suction catheter could not pass beyond approximately $10 \mathrm{~cm}$ from the tube connector. We found that the pressure-volume loop and flowvolume loop showed obstructive patterns compared to the initial ones (Fig. 1A). In addition, $\mathrm{ETCO}_{2}$ and PIP increased to $48 \mathrm{mmHg}$ and $30 \mathrm{cmH}_{2} \mathrm{O}$ (preset pressure limit), respectively; the $\mathrm{SpO}_{2}$ level was maintained at $99 \%$. The fiberoptic bronchoscope was inserted, but we could not advance it past $10 \mathrm{~cm}$; we found that the swelling of the internal wall of the tube was obstructing the lumen of the tube (Fig. 2A). We immediately replaced the ETT with a new one after the patient was placed in a supine position. Subsequently, the PIP was reduced to $15 \mathrm{cmH}_{2} \mathrm{O}$ and all other parameters normalized rapidly (Fig. 1B). The surgery was successful. The patient did not have any symptoms related to barotrauma and recovered well without complications.

\section{DISCUSSION}

Endotracheal intubation is the gold standard for airway
A

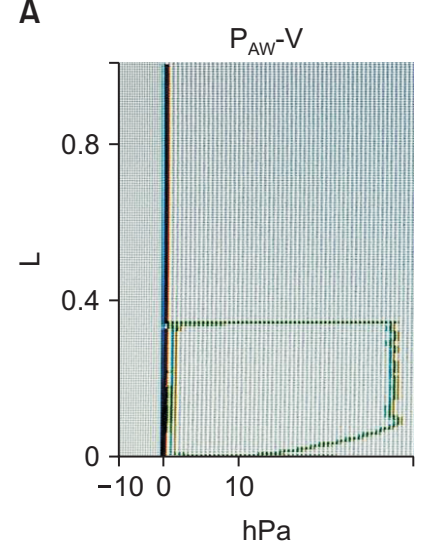

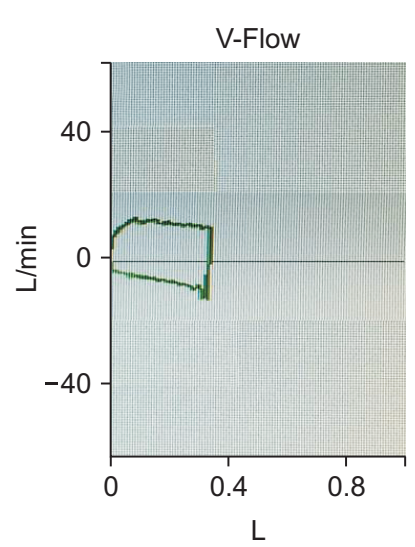

B
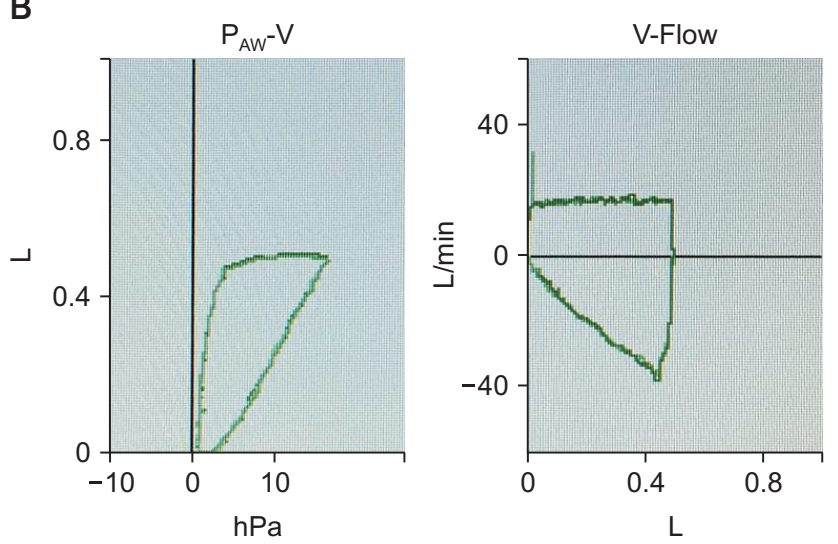

Fig. 1. Recovery from obstructive pattern of loops after endotracheal tube replacement. (A) Right and downward shifting in pressurevolume loop and diminished expiratory flow in flow-volume loop (calibrated scale), which indicates an obstructive pattern compared to $B$. (B) Normalized loops after tube replacement with similar values before peak inspiratory pressure elevation.
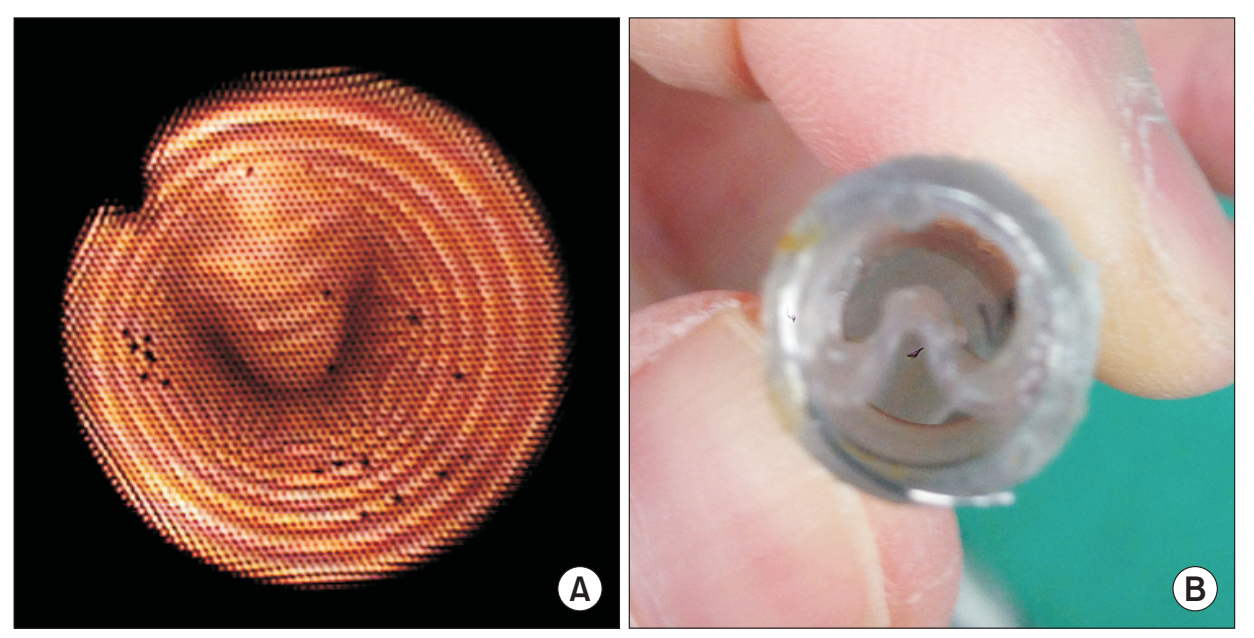

Fig. 2. Fiberoptic bronchoscopic and cross-sectional view of the reinforced endotracheal tube (ETT). (A) Fiberoptic bronchoscopic view showing the ETT lumen that is obstructed by the bulging inner wall. (B) Photograph of the cross-sectioned ETT showing the dissected inner wall bulging into the lumen. 
management because it can establish a definitive airway, provide maximal protection against the aspiration of gastric contents, and allow positive pressure ventilation [2]. Furthermore, high concentrations of oxygen, other gases, or volatile anesthetics, as well as some medications, can be administered to patients via ETT [3]. However, laryngoscopy and endotracheal intubation are associated with complications such as hypoxia, hypercarbia, dental and airway trauma, tube malpositioning, physiological responses to airway instrumentation, or tube malfunction [4]. These complications can occur during airway management, including during laryngoscopy and intubation, while the tube is in place, or following extubation. Kinking or biting of the tube, thick or inspissated mucus, or blood in the lumen can lead to obstruction of the ETT, which may cause ventilatory failure, and such an occurrence is sometimes observed. Valve or cuff damage also results in ETT malfunction; their integrity should be verified prior to use. Furthermore, polyvinyl chloride tubes may be ignited by cautery or laser in an oxygen/nitrous oxide-enriched environment. Therefore, a patent airway is not guaranteed by only keeping ETT in place. Furthermore, the ETT itself may cause airway obstruction [5].

Armored ETTs are cuffed, wire-reinforced, silicone rubber tubes that are quite flexible but difficult to compress or kink. This can make them useful for fiberoptic intubation, intubation through a tracheostomy, head and neck cases, neurosurgical cases, and patients placed in the prone position [6] However, intraoperative airway obstruction caused by malfunction of a reinforced ETT has been previously reported. It is relatively easy to identify tube obstruction caused by biting on the tube [7] or by kinking [8] that results in compression of the reinforcing coils, which leads to narrowing of the lumen irreversibly. It is more difficult to recognize tube obstruction from rare causes, such as dissection of the inner membrane of a reinforced ETT. Most of these cases were caused by exposure to heat during resterilization of the ETT [9-11], use of $\mathrm{N}_{2} \mathrm{O}$ during anesthesia $[10,12,13]$, damage to the inner wall because of stretching of the ETT [9], or forceful manipulation of the stylet. Choi et al. [14] reported dissection of the inner wall of a new reinforced ETT without any $\mathrm{N}_{2} \mathrm{O}$; however, there was unusual resistance during stylet insertion before use. In this case report, we used a newly unpacked reinforced ETT and did not stretch or press the ETT during intubation or patient positioning. We felt some resistance during the stylet manipulation, although it was not markedly more than usual; we also used $\mathrm{N}_{2} \mathrm{O}$ after intubation. Because of the greater solubility of $\mathrm{N}_{2} \mathrm{O}$ compared to $\mathrm{N}_{2}$, either the volume (if distensible) or the pressure (if non-distensible) of the air-containing space is increased during exposure to $\mathrm{N}_{2} \mathrm{O}$ [15]. Together with the use of $\mathrm{N}_{2} \mathrm{O}$ and careless manipulation of the stylet, the possibility of a manufacturing error, in which tiny air bubbles are included in the wall $[9,12,13]$, might have been the cause of the inner wall dissection.

In the prone position, ventilatory distress may be a serious complication [13]; if it was caused by the ETT, the problem would be more detrimental to the patient because of the difficulty in changing the tube rapidly. Fortunately, we detected the ETT obstruction and changed it before the skin incision was performed, which might have delayed the changing of the tube. The differential diagnosis for ventilatory distress included consideration of pneumothorax and bronchospasm. In this case, auscultation of both lungs remained possible; breath sounds were found to be normal, and Ventolin administration for bronchodilation was not effective. However, the changes in the pressure-volume loop, which shifted to the right and downward; changes in the flow-volume loop, with diminished expiratory flow; and failure to advance the suction catheter led us to conclude that there was a problem with the ETT. Furthermore, the fiberoptic bronchoscope allowed us to visualize the ETT lumen that was obstructed by the bulging inner wall; thus, we decide to change it. After the ETT was changed, the cross-sectioned ETT was found to have a dissected inner wall that bulged into the lumen (Fig. 2B).

In conclusion, intraoperative airway obstruction can result from rare causes, such as dissection of the internal wall of reinforced ETT. For patient safety, it is necessary to recognize the possibility of airway obstruction due to a rare cause and to monitor patients vigilantly when they are under anesthesia.

\section{REFERENCES}

1. Szekely SM, Webb RK, Williamson JA, Russell WJ. The Australian Incident Monitoring Study. Problems related to the endotracheal tube: an analysis of 2000 incident reports. Anaesth Intensive Care 1993; 21: 611-6.

2. Thomas EB, Moss S. Tracheal intubation. Anaesth Intens Care Med 2017; 18: 1-3.

3. Raehl CL. Endotracheal drug therapy in cardiopulmonary resuscitation. Clin Pharm 1986; 5: 572-9. 
4. Divatia JV, Bhowmick K. Complications of endotracheal intubation and other airway management procedures. Indian J Anaesth 2005; 49: 308-18.

5. Hosking MP, Lennon RL, Warner MA, Gray JR, Masley P, DeLuca LA, et al. Endotracheal tube obstruction: recognition and management. Mil Med 1989; 154: 489-91.

6. Haas CF, Eakin RM, Konkle MA, Blank R. Endotracheal tubes: old and new. Respir Care 2014; 59: 933-52; discussion 952-5.

7. Ball JE, Platt S. Obstruction of a reinforced oral tracheal tube. Br J Anaesth 2010; 105: 699-700.

8. Peck MJ, Needleman SM. Reinforced endotracheal tube obstruction. Anesth Analg 1994; 79: 193.

9. Paul M, Dueck M, Kampe S, Petzke F. Failure to detect an unusual obstruction in a reinforced endotracheal tube with fiberoptic examination. Anesth Analg 2003; 97: 909-10.

10. Rao GS, Ali Z, Ramkiran S, Chandrasekhar HS. The dissection of a reinforced endotracheal tube causing near-fatal intraoperative airway obstruction. Anesth Analg 2006; 103: 1624-5.

11. Jeon YS, Kim YS, Joo JD, Kang EG, In JH, Choi JW, et al. Partial airway obstruction caused by dissection of a reinforced endotracheal tube. Eur J Anaesthesiol 2007; 24: 983-4.

12. Park SH, Shin YD. Partial airway obstruction due to intraluminal bulging of the inner layer of a reinforced tube : a case report. Anesth Pain Med 2009; 4: 68-70.

13. Santos IA, Oliveira CA, Ferreira L. Life-threatening ventilatory obstruction due to a defective tracheal tube during spinal surgery in the prone position. Anesthesiology 2005; 103: 214-5; discussion 215.

14. Choi E, Cho HS, Lee JW. Intraoperative airway obstruction from a whole dissection of the inner wall of a reinforced endotracheal tube. Korean J Anesthesiol 2013; 65: 585-6.

15. Eger EI 2nd, Saidman LJ. Hazards of nitrous oxide anesthesia in bowel obstruction and pneumothorax. Anesthesiology 1965; 26: 61-6. 